\title{
Smart Waste Management System using IBM Watson Services
}

\author{
Ch Tejasri
}

\begin{abstract}
In present developed or developing countries wastage managements are one in the primary problems. This main issues to wastage managements to the overload of garbage bins, which spills out results in pollution and leads to spread diseases. The detection, monitoring, management of wastage into wastage bin as a complex processes that takes more humans effort, time \& cost while it is not suitable for presents day technology. The main aim is to design a system based using IBM Watson IoT methodology for collecting garbage from the particular area whose garbage bins are overflowing. These are papers proposes at a smart alert systems with the clear of garbage by giving continuous notifications to the receiver for cleaning the dustbins. This process is done by the sensor which is used as checking in the levels to garbage fills to the waste bins \& sending notifications to this municipal collection department. This is android application is used as intimates in the alert with micro controllers as the urbanoffice \& to performed in the remote monitor to the cleaning process. The notifications are sent as android application using Wi-Fi module.
\end{abstract}

Keywords-Aurdino UNO, GPS, Ultrasonic sensor, IBM WATSON IoT, NodeMCU.

\section{INTRODUCTION}

$S_{\text {orm }}$ the wastes with its commencement as finally disposals. It is included in the collections, transportations, \& disposal into waste towards as monitors \& directive. Different countries and regions use different methods for the collections to the waste. still the locally governments authority provides as a number of service as collecting domestic wastes. The road sides collected are the mostly commons technique of the disposals into most country, into when it is waste are collecting as at regularly interval among the specializes truck. The collecting as waste are transports in the appropriate disposals areas. The waste collection method in such countries is an on-going challenge and many struggles due to weak institutions and rapid urbanization.

Required to improvements into waste management systems:

All most two \& third to the world populations can live in cities by 2030 so required perfect solutions for these technology of urban life. The main key to the issue of health is waste management. Efficiently to usage \& handled to the resource as happen to more importants form future cities. The demands for future cities are efficiently \& energy saves as waste management's, reduces as co2, airpollution, \& vehicle drain emission. Waste management's to the important into developers as country. Waste management can consume up to 50 percent of the city budgets, but serves only a fraction of the population. Sometimes, up to $60 \%$ of the wastage as not collects, this are often burns down the road. It's contaminates drink waters, which spreads the diseases as people lives nearby. Despite greatly routes as optimists; the works have to physical going to Dustbin into check form waste level. Form these reason, truck often visited container than don't needs spaces, which is a waste of both time and fuel. Reduces in the quantity and hazards properties as residentially \& industrial wastes will reduce watermanagement without harming human health and the environment. Pollution will be reduced by improving the management of the waste; useful materials will be recycled and will create more green energy.

\section{METHODOLOGY}

Ultrasonic sensor:

These are sensors to use as detected in the levels as the dusts into dust bins. It uses a sound transmitter and receiver. The ultrasonicsensor creates an ultrasonicpulse known as the pings \& listened to the pulse reflectance. Sound Pulses are create electronic uses as sonar projector equipped with a signal generators, poweramplifier \& electro acoustic transducesr arrays. In the beam front is usually used as concentration sound energy into the beam.

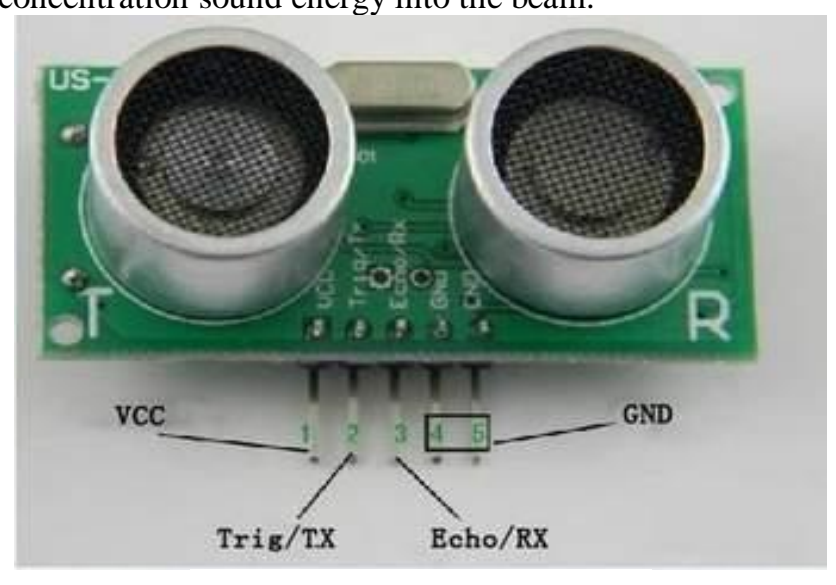

VCC-5V of power supply

TRIG-Trigger Pin

ECHO-Echo Pin

GND- To Ground 
Node MCU (ESP8266):

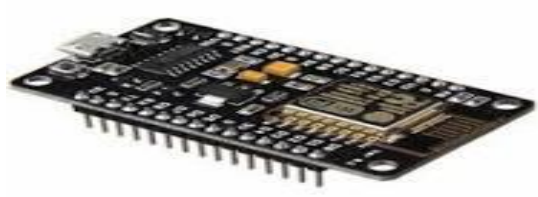

ESP8266 as Wi-Fi enabled system on chip (SoC) module developed by Espressif system. The main use form developments of the IoT (Internet of Things) embedded application. ESP8266 module at low cost standalone wireless transceiver may be use form end-point IoT development.

\section{PROPOSED APPROACH}

The idea has been proposed to design on smarts bin for an ultrasonic sensor. Previously existed method that involved as composite circuit \& higher cost \& feature is lesser. It is an expensive trash bins, it's non at priorityexperiment with peoples. This is there are deploys as like as kinds to system than as not one cheapest so within extend feature that have not at all implements. Form detections as the trashes into the bins, as many sensor may be uses such as moisture sensors, IR sensor form detections in wet \& dry wastes. In this paper the proposed system would be able to automate the waste monitoring and management of overall collection process using IBM Watson IoT \& also have a great user interface to see the root mapping placement of bins in the city. In this whenever the waste bins gets filled this is acknowledged by placing the circuit at the waste bin which transmits it to the receiver. The MIT App Inventor is used to develop an android application to send the continuous notifications to the municipal officer.

\section{Block Diagram:}

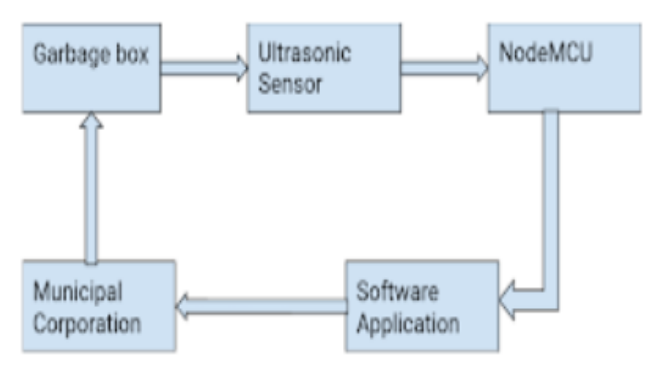

\section{Working Principle:}

The trash contained as transmitting signal as indicate than we are over 80 percent or 90 percent full $\&$ can be empty. The signals are sent to the web-based software application via mobile communication used by the management company. In software, the capacity of the container is indicated, which can be used as a basis for planning the best way to collect the garbage. A strong ultrasonicsensor as installation to the trash contains \& detected in the filler levels regard as when it is deposited inside. This is entire systems consists of an ultrasonicsensor, a nodeMCU, and a power supply. The sensor is fixed to garbage bin. At connections among the nodeMCU \& sensors as making to the helping as the connect wire. This works as programming to fed as the nodeMCU. The power supplying as the systems are gives us the helping to the batteries.

\section{Flowchart:}

In flowchart in the paper as shows into figure. The basic provides techniques are projects. This process as the paper to smart WasteManagement Systems beginning for options started. Ultrasonicsensors is places in that sensing in the levels of the waste in the bins \& while is crossed in the maximum levels, messages will sending as the concern authorities as therefore in the concerns as authorities may cleaned in the dust bins immediately. This process will repeats itself again and again until the dustbin is not cleaned.

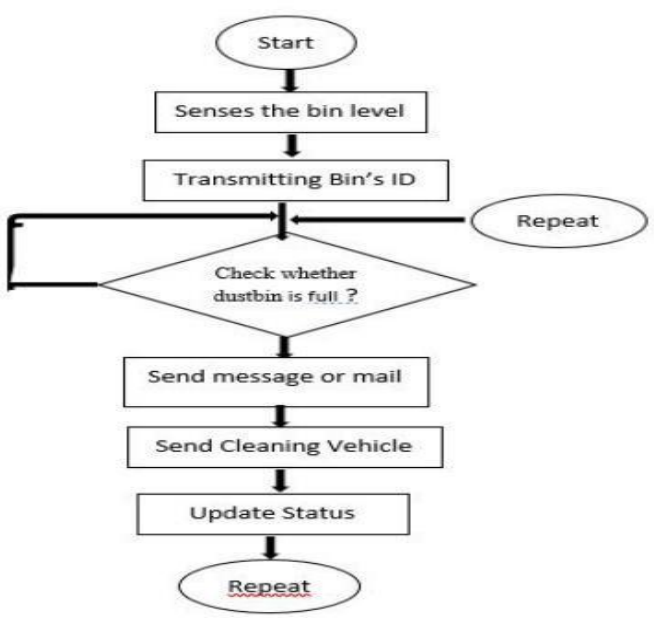

IV. RESULTS

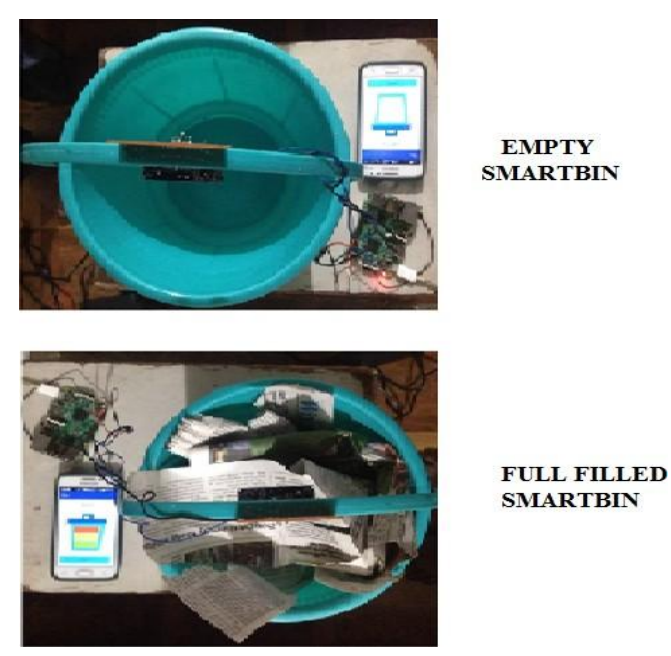

\section{CONCLUSION}

Among these techniques, waste collections into the cities become easiest. And can reduce airpollution, trafficflow, manpower, times and money. From the helping to the right technologies as GPS and Software Application, So will be guides in the trucking at choosing the short route with garbage collections. The paper is could adding to edges on city with the goal of being smart and public friendly.

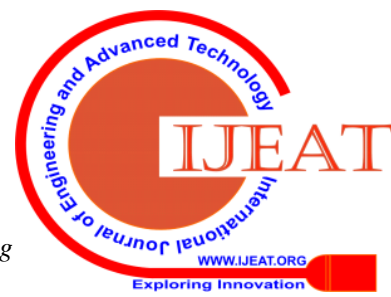




\section{FUTURE SCOPE}

The range with future works is that the systems may be implements within a timestamp, while it shows the real time clocks in the concerned persons in which is time the Dust bins are filled and collect the waste for Smart Dustbin. In future smart waste management is implementing with big data.

\section{REFERENCES}

1. KanchanMahajan, "Waste Bin Monitoring System Using Integrated Technologies", International Journal of Innovative Research in Science, Engineering and Technology, Issue 3, Issue 7, July2014.

2. Raghu Mani Singh, C. Dye, M. Solid waste management of Thou ball Municipality, Manipur- a case have a look at Green Technology and Environmental Conservation (GTEC 2011), 2011 International Conference Chennai $21-24$

3. Vikrant Abhor, "Smart Garbage control System International Journal of Engineering Research \& Technology (IJERT), Vol. Four Issue03, March-20152000.

4. Narayan Sharma, "Smart Bin Implemented for Smart City", International Journal of Scientific \& Engineering Research, Volume 6, Issue9, September-2015

5. S.S.Navghane, M.S.Killedar, Dr.V.M. Rookie, "Iota based clever garbage and waste collection bin", global journal of improve research in electronics and conversation engineering, extent five, Issue five, May 2016 